\title{
A germinating seed found in human ear: A case report
}

\author{
Nwosu J. N. ${ }^{1}$, Ohaneme A. ${ }^{2}$, Mgbafulu D. I ${ }^{2}$ \\ 1. University of Nigeria Teaching Hospital, Enugu, Nigeria. 2. Imo State University Teaching Hospital, Orlu, Nigeria. \\ Correspondence: Nwosu J. N. Address: Department of Otorhinolaryngology, University of Nigeria teaching hospital, \\ Enugu PMB 01129, Enugu, Nigeria. Email: nwosujn@yahoo.com
}

Received: April 25, 2014

DOI : $10.5430 /$ crim.v1n2p227
Accepted: June 8, $2014 \quad$ Online Published: July 30, 2014

URL: http://dx.doi.org/10.5430/crim.v1n2p227

\section{Abstract}

Foreign body lodgment in ear is a common problem in Otolaryngological practice. An unusual case of seed germinating in the ear of a 9 year old girl out of poverty, neglect and ignorance is presented.

\section{Keywords}

Human ear, Germinating seed, Foreign body

\section{Introduction}

Foreign Body (FB) in the ear is not an uncommon problem more so in the paediatric population. The profile vary; it could be classified as animate and inanimate. The inanimate foreign bodies can be classified as vegetative and non-vegetative foreign bodies, and hygroscopic and non-hygroscopic; and may include seeds, nuts, grains and others. The most common ear foreign bodies include beads, plastic toys, pebbles, and popcorn kernel ${ }^{[1]}$. The common animate foreign bodies found in the ear include cockroaches and beetles ${ }^{[2]}$. Animals (for example, ants, moths, flies, etc) are common foreign bodies in the adult ear and often require immediate attention as they cause pain and agitation in the patient ${ }^{[3]}$.

The aims of this study are to report the occurrence of a germinating seed (Icheku)* in the external auditory canal and highlight the circumstances leading to it. The nature of which is interesting. We did not find any case of foreign body seed germinating in aural canal reported in the literature locally or otherwise.

\section{Case report}

A 9 year old female presented to the Ear Nose Throat ( ENT ) Clinic of Imo State University Teaching Hospital, Orlu via the Children's Out Patient Clinic (CHOP) with a complaint of left otalgia. Otalgia was severe and has been progressive for about 1 week. There was associated copious purulent foul smelling discharge. She stated that 5 months ago while sleeping one of the siblings inserted a seed (Icheku) into her left ear canal. There was no pain or ache following the insertion but there has been feeling of fullness of the affected ear. She denied any attempt at removing the seed or application of any form of medication. No medical attention was sort for because of lack of funds. The otalgia and discharge attracted the attention of a neighbor who brought her to the Children's Out Patient Clinic from where she was referred to the ENT clinic. She denied any other symptoms and was otherwise medically fit. She is the second in a monogamous family of 12 children (mother had 2 sets of twin). Mother is a petty trader and father a motor-cyclist. On examination she was a young 
girl in no obvious respiratory distress. She was afebrile, not pale and anicteric. Her temperature was $37^{\circ} \mathrm{C}$, pulse rate 96 beats $/ \mathrm{min}$ and weight $30 \mathrm{~kg}$. On examining the ears with otoscope, the right ear was essentially normal. In the left ear there was periauricular oedema with tragal tenderness. The external auditory canal was filled with purulent discharge. Careful gentle dry mopping revealed brownish, smooth-surfaced substance in the external auditory canal. The tympanic membrane (TM) was not visible. Rhinne test was positive in the right ear and negative in left ear. Weber test lateralized to the left ear. Pure tone audiometry was not done due to the condition of the affected ear.

The foreign body was removed with forceps turned out to be the shell of a seed (see Figure 1, 2). Repeat otoscopy showed the cotyledon of the germinating seed inside the external auditory canal. Complete removal revealed the TM was intact, dull and oedematous. The EAC also appeared oedematous especially around the area of seed impaction harbouring a circular area of necrosis. The EAC was further cleaned and Tuning fork test repeated without any change in the result. Patient was given topical antibiotics and analgesics, and appointment given for follow up. She however did not show up again.

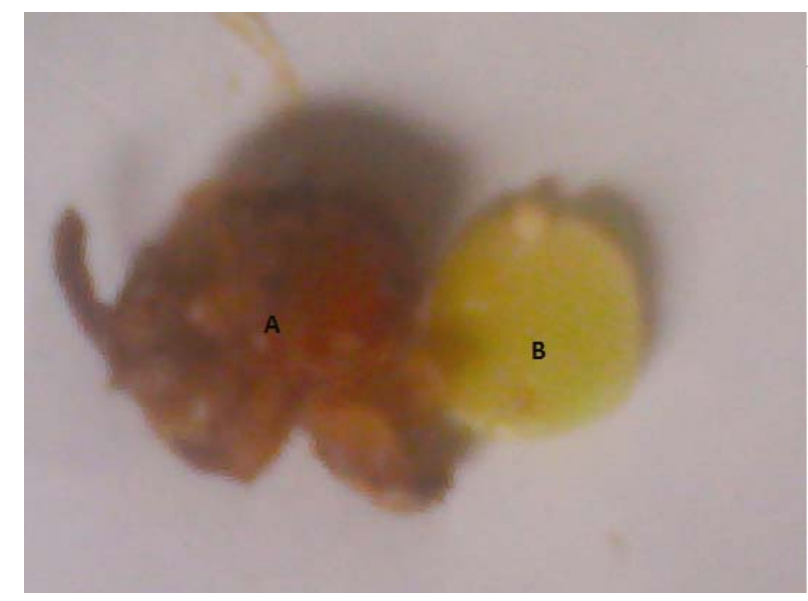

Figure 1. The seed coat (A) and cotyledon (B) removed from the ear.

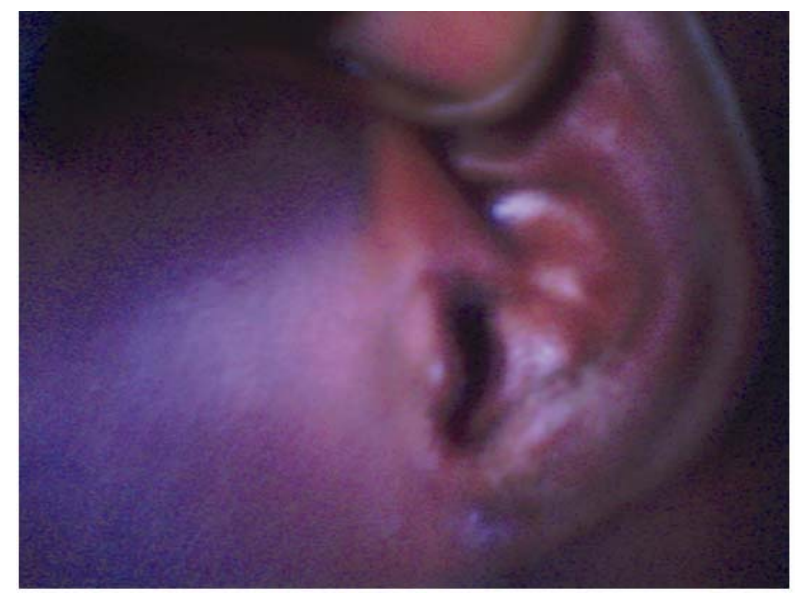

Figure 2. The ear after the removal of the germinating seed.

\section{Discussion}

The aetiology of foreign bodies in nose or ear has been ascribed to the general curiosity and a whim to explore orifices in children, playful insertion of foreign bodies into others' body parts, accidental entry of foreign body, preexisting disease in ear causing irritation, habitual cleaning of ear and nose with objects like ear buds ${ }^{[4]}$. It was once thought that the tendency of a few children to inflict foreign body upon self or others is a kind of childish attitude. A foreign body in the ear may result in significant morbidity because of the small anatomic size and delicate skin of the EAM and the thinness of the tympanic membrane ${ }^{[1,5]}$. Vegetable foreign bodies as in the index case if left untreated, disintegrate to liberate irritant vegetable oil and inflammation sets in. Beyond this the foreign body here sprouted and the cotyledons were intact. Typical in the case is the neglect, and apparent show of no concern by the parents due to poverty and ignorance. The case was clinically silent until pain and suppuration set in and that attracted the attention of a neighbor. Silent cases could pose a diagnostic problem but the case was witnessed and so could have been removed without consequence if the child was attended to early. In many cases, patients with foreign bodies in the ear are asymptomatic, and in children the foreign body is often an incidental finding ${ }^{[6]}$. Unusual cases of foreign body in the ear have been reported ${ }^{[7-9]}$, the case of a germinating seed in the ear was not found to have been reported previously in our review of literature. 


\section{Conclusion}

We conclude that the case of germinating seed in the ear is an unusual clinical situation. Poverty, ignorance and overcrowding still impact negatively on health care delivery in our environment. Advocacy on sizeable manageable family should be strengthened.

\section{References}

[1] Ansley JF, Cunningham MJ. Treatment of aural foreign bodies in children. Pediatrics. 1998; 101(4 pt 1): 638-641. http://dx.doi.org/10.1542/peds.101.4.638

[2] Sarkar S,Roychoudhury A, Roychaudhuri BK. Foreign bodies in ENT in a teaching hospital in Eastern India. Indian J Otolaryngol Head Neck Surg. 2010 April-June; 62(2): 118-120. http://dx.doi.org/10.1007/s12070-010-0040-6

[3] Bressler K, Shelton C. Ear foreign body removal: a review of 98 consecutive cases. Laryngoscope 1993; 103: 367-370. http://dx.doi.org/10.1002/lary.5541030401

[4] Das SK. Aetiological evaluation of foreign bodies in the ear and nose. J Laryngol Otol. 1984; 98: 989-991. http://dx.doi.org/10.1017/S002221510014784X

[5] Ijaduola GT, Okewo PA. Foreign body in the ear and its importance; the Nigerian experience. J Trop Pediatr. 1986; 32: 4-6. http://dx.doi.org/10.1093/tropej/32.1.4

[6] DiMuzio J Jr , Deschler DG . Emmergency department management of foreign bodies of the externa ear canal in children. Otol Neurotol 2002; 23: 473-475. http://dx.doi.org/10.1097/00129492-200207000-00014

[7] Cimolai N, Cimolai TL. Otitis from the common bedbug. The Journal of Clinical and Aesthetic Dermatology December. 2012 ; 5(12): 43-45 .

[8] Bala A , Purushotman R , Lina LC, Avatar S. Superglue Accidentally Used As Ear drops. Med J Malaysia. 2012 April; 67(2); 212-213.

[9] Arora S , Goyal SK. Unusual foreign body in the ear in an adult with psychiatric illness. Indian Journal of Psychiatry. 2009 Apr -Jun; 51(2): 164. http://dx.doi.org/10.4103/0019-5545.49467 